연구노트

\title{
Effect of calcium chloride on the texture of pickled radish wrap
}

\author{
Eun-Jeong Jeong ${ }^{1,2}$, Nam Keun Lee ${ }^{1,2}$, Eun Ji Yum ${ }^{2}$, Kang $\mathrm{Nam}^{2}$, Jisun $\mathrm{Oh}^{1,2}$, \\ Yong-Sik Kim ${ }^{1}$, Jun-Young $\mathrm{Park}^{3}$, Su-Jeong Kim ${ }^{3}$, Yong-Seob Jeong ${ }^{2 *}$ \\ ${ }^{1}$ Research Center for Industrial Development of Biofood Materials, Chonbuk National University, Jeonju 561-756, Korea \\ ${ }^{2}$ Department of Food Science and Technology, Chonbuk National University, Jeonju 561-756, Korea \\ ${ }^{3}$ Korea Pickle Co., Ltd., Sunchang 595-804, Korea
}

\section{염화칼슘 첨가에 따른 쌈무의 조직감 개선 효과}

\author{
정은정 ${ }^{1,2} \cdot$ 이남근 ${ }^{1,2} \cdot$ 염 은지 $^{2} \cdot$ 남강 $^{2} \cdot$ 오지선 ${ }^{1,2} \cdot$ 김용식 $^{1} \cdot$ 박준영 $^{3} \cdot$ 김수정 $^{3} \cdot$ 정용섭 $^{2 *}$ \\ ${ }^{1}$ 전북대학교 바이오식품소재개발 및 산업화연구센터, ${ }^{2}$ 전북대학교 식품공학과, ${ }^{3}$ 농업회사법인 한국절임(주)
}

\begin{abstract}
This study was conducted to evaluate the quality characteristics of pickled radish wrap supplemented with calcium chloride $\left(\mathrm{CaCl}_{2}\right)$ at different concentrations. With $\mathrm{CaCl}_{2}$ supplementation, initial $\mathrm{pH}$ and acidity were $3.8 \sim 4.0$ and 2.7 3.0\% (w/v), respectively. During the 28 day-preservation at $4^{\circ} \mathrm{C}$ or $50^{\circ} \mathrm{C}$, the initial $\mathrm{pH}$ and acidity were maintained. However, when the pickled radish wrap was preserved at $25^{\circ} \mathrm{C}$, it had lower $\mathrm{pH}$ (by 0.5 ) and higher acidity (by 1.9 2.2\%) when compared with the initial values. The difference in color ( $\triangle E$-value) of the pickled radish wrap preserved at $50^{\circ} \mathrm{C}$ was significant $(\triangle \mathrm{E}$-value $23 \sim 27)$, though the hardness of the sample prepared at $4^{\circ} \mathrm{C}$ or $25^{\circ} \mathrm{C}$ showed no distinguishable differences at various concentrations of $\mathrm{CaCl}_{2}$ supplementation $(0.1,0.2,03,0.4$, and $0.5 \%$ ). However, once preserved at $50^{\circ} \mathrm{C}$, it resulted in the greater hardness with the higher concentrations of $\mathrm{CaCl}_{2}$ supplementation. In terms of softness, the overall trend in changes was similar to the hardness. A sensory evaluation using the samples preserved at $4{ }^{\circ} \mathrm{C}$ for 28 days demonstrated that the preparation with $0.4 \% \mathrm{CaCl}_{2}$ ranked highest in taste, hardness and overall acceptability. It wass suggested that supplementation with $0.4 \% \mathrm{CaCl}_{2}$ would be most appropriate to improve the textural properties of pickled radish wrap while maintaining its organoleptic quality.
\end{abstract}

Key words : pickled radish wrap, calcium chloride, hardness, quality characteristics

\section{서 론}

무(Raphanus sativus L.)는 원산지가 중앙아시아로 온대 아시아와 유럽에 널리 재배되고 있으며, 배추와 함께 국내의 2대 채소 중의 하나이며 무김치(섞박지, 깍두기, 동치미 등) 로 주로 이용된다. 이외에 현재 무를 이용한 가공식품으로는 단무지, 무피클과 무잼 등이 있으며, 식생활의 변화와 다양 화로 김치 이외의 무 가공품의 소비가 증가되고 있다(1).

*Corresponding author. E-mail : ysjeong@jbnu.ac.kr Phone : 82-63-270-4819, Fax : 82-63-270-4344

Received 5 December 2014; Revised 8 April 2015; Accepted 21 April 2015.

Copyright (c) The Korean Society of Food Preservation. All rights reserved.
쌈무는 식초에 껍질을 벗긴 무를 침지하여 일정 시간 숙성시킨 후 얇게 잘라 쌈무의 맛 향상, 갈변현상 및 부패방 지를 위해 조미액(정제수, 감미료, 식초, 유기산류 및 보존제, 정제염 등)을 첨가한 것으로 국내에서는 고기 또는 다양한 음식 재료를 싸 먹을 수 있는 용도로 소비되는 대표적인 무피 클 중의 하나이며 식품공전상 절임식품으로 분류된다(2).

일반적으로 쌈무의 유통기한은 냉장상태에서 대략 60 90일이나 저장기간 동안 쌈무의 조직이 연화되는 문제 점을 가지고 있다. 식물 조직의 연화는 여러 가지 원인에 의해서 발생되지만 주요원인으로는 pectin esterase와 polygalacturonase 효소에 의한 펙틴질의 성상 변화로 알려 지면서 식품 사용이 가능한 첨가물인 염화나트륨 $(\mathrm{NaCl})$ 과 염화칼슘 $\left(\mathrm{CaCl}_{2}\right)$ 첨가 또는 예열처리와의 병행 등을 통해 polygalacturonase 효소를 불활성화시켜 연화현상을 방지하 
여 왔다 $(3,4)$. 특히 염화칼슘은 $\mathrm{Ca}^{2+}$ 이 펙틴질과 $\mathrm{Ca}$-pectate 를 형성함으로써 연화현상 억제와 식물조직의 경도를 증가 시키는 효과가 있음이 알려져 있다 $(3,5)$. 이에 따라 국내에 서도 최근까지 김치, 오이지, 단무지, 사과와 버섯 등 다양한 식품에서 염화칼슘의 첨가에 따른 저장성에 관한 연구가 지속적으로 보고되었다(6-10).

식품에 염화칼슘의 국내 사용기준은 1998년 식품의약품 안전처의 식품첨가물의 기준 및 규격 고시(제98-59호)에 따라 기존 칼슘으로서 식품의 $1 \%$ 이하의 사용기준량이 삭제되어 식품제조 또는 가공에 사용되는 양은 현재 정해져 있지 않으나(11), 쓴맛으로 인해 식품마다 관능적인 면을 고려하여 물리학적 및 영양학적인 효과를 낼 수 있는 최소 량이 사용되고 있는 것으로 판단된다.

쌈무에 대한 연구에 있어서는 다시마 샐러드 드레싱에 절인 쌈무의 관능 평가(12) 이외에 현재까지 쌈무에 관한 연구는 거의 보고된 바 없으며, 대부분은 제품제조에 초점 이 맞춰져 있다.

따라서 본 연구는 염화칼슘 첨가에 따른 쌈무 조직의 경도에 미치는 효과를 검토하고 품질의 변화를 비교하여 쌈무에 투입되는 염화칼숨의 적정 유효량에 대한 기초자료 를 제공하고자 한다.

\section{재료 및 방법}

\section{실험재료}

쌈무 제조에 사용된 무는 2014년도에 재배된 순창지역의 무를 사용하였으며, 조미액의 원료인 정제소금(한주청정 소금, Korea), 소르빈산칼륨(Qingdao Fuso Refining and Processing Co., LTD., China), 삭카린나트륨((주)JMC, Korea), 구연산(RZBC, China), 호박산이나트륨(Nippon Shokubai Co., LTD., Japan), 폴리인산나트륨(서도비엔아 이, Korea), 아황산나트륨(Kamisu Chemical Co., LTD., Japan), 빙초산(삼양산업, Korea), 비타민 C(Hebei Welcome Pharmaceutical Co., LTD., China), 글리신(Showa Denko, Japan), 염화칼슴(OCI, China)을 구입하여 실험에 사용하였 다.

\section{쌈무 제조}

쌈무의 제조는 무를 세척하고 지름이 $8.5 \sim 10 \mathrm{~cm}$ 되도록 박피 및 비가식부위를 절단한 후 $1.4 \mathrm{~mm}$ 두께로 슬라이스 하였다. Table 1 의 비율로 조미액 및 무를 용기에 투입 후 밀봉하였다. 처리된 시료는 $10^{\circ} \mathrm{C}$ 이하에서 48 시간 숙성 후 $4^{\circ} \mathrm{C}, 25^{\circ} \mathrm{C}$ 그리고 염화칼슘 처리량에 따른 쌈무 시료들의 경도의 변화를 좀 더 명확하게 분석하고자 $50^{\circ} \mathrm{C}$ 로 가혹성 평가 온도를 설정하고 28 일 동안 저장하면서 실험에 사용 하였다.
Table 1. Mixing ratio of the ingredients used in making pickled radish wrap

\begin{tabular}{lcccccc}
\hline \multicolumn{1}{c}{ Ingredients (\%) } & 0 & 0.1 & 0.2 & 0.3 & 0.4 & 0.5 \\
\hline Radish & 60.00 & 60.00 & 60.00 & 60.00 & 60.00 & 60.00 \\
Salt & 2.00 & 2.00 & 2.00 & 2.00 & 2.00 & 2.00 \\
Potassium sorbate & 0.09 & 0.09 & 0.09 & 0.09 & 0.09 & 0.09 \\
Sodium saccharin & 0.04 & 0.04 & 0.04 & 0.04 & 0.04 & 0.04 \\
Citric acid & 0.03 & 0.03 & 0.03 & 0.03 & 0.03 & 0.03 \\
Succinic acid & 0.02 & 0.02 & 0.02 & 0.02 & 0.02 & 0.02 \\
Vitamin C & 0.01 & 0.01 & 0.01 & 0.01 & 0.01 & 0.01 \\
Glycine & 0.01 & 0.01 & 0.01 & 0.01 & 0.01 & 0.01 \\
Sodium polyphosphate & 0.04 & 0.04 & 0.04 & 0.04 & 0.04 & 0.04 \\
Sodium sulfite & 0.01 & 0.01 & 0.01 & 0.01 & 0.01 & 0.01 \\
Glacial acetic acid & 0.58 & 0.58 & 0.58 & 0.58 & 0.58 & 0.58 \\
Water & 37.17 & 37.07 & 36.97 & 36.87 & 36.77 & 36.67 \\
Calcium chloride & 0.00 & 0.100 & 0.200 & 0.300 & 0.400 & 0.500 \\
Total & 100.00 & 100.00 & 100.00 & 100.00 & 100.00 & 100.00 \\
\hline
\end{tabular}

\section{$\mathrm{pH}$ 및 적정산도 측정}

쌈무의 $\mathrm{pH}$ 는 쌈무액을 채취하여 $\mathrm{pH}$ meter(PP-15, Sartorius Co., Goettingen, Germany)를 이용하여 상온에서 측정하였으며, 적정산도는 쌈무액을 증류수로 5 배 희석한 후 페놀프탈레인 시약을 첨가한 뒤 $0.1 \mathrm{~N} \mathrm{NaOH}$ 로 적정하여 acetic acid양으로 환산하였다.

\section{색도 측정}

쌈무의 색도는 색차계(SP-80, Tokyo Denshoku Co., Tokyo, Japan)를 이용하여 L(lightness), a(redness), $\mathrm{b}$ (yellowness) 값을 3반복 측정한 후 평균값으로 나타내었 다. 이때 표준백판의 $\mathrm{L}$ 값은 $91.85, \mathrm{a}$ 값은 $0.35, \mathrm{~b}$ 값은 0.41 이 었으며, 0 일차의 시료를 대조구로 하여 기간에 따른 색차 $\triangle \mathrm{E}$ 값을 $\triangle E=\sqrt{\triangle L^{2}+\triangle a^{2}+\triangle b^{2}}$ 의 식으로 구하였다. $\Delta \mathrm{E}$ 의 값이 $0 \sim 0.5$ 는 색차가 거의 없는 경우이고, $0.5 \sim 1.5$ 는 근소 한 차이, $1.5 \sim 3.0$ 은 감지할 수 있을 정도의 차이, 3.0 6.0은 현저한 차이, 6.0 12는 극히 현저한 차이, 12 이상은 다른 계통의 색으로 해석하였다.

\section{조직감(경도와 씹힘성) 측정}

시료를 texture analyzer(TA-XT2, Stable Micro System Co., Haslemerd, England)를 이용하여 10회 반복하여 측정 하였다. 측정조건은 쌈무의 지름에 맞는 blade probe의 넓은 면을 사용하였으며, test speed $1.0 \mathrm{~mm} / \mathrm{sec}$, pre-test speed $1.0 \mathrm{~mm} / \mathrm{sec}$, strain $80 \%$ 의 조건으로 TPA mode를 사용하여 측정하였다.

\section{관능평가}

쌈무의 관능평가는 저장온도 $4^{\circ} \mathrm{C}$, 저장 28 일째의 쌈무를 
이용하여 실시하였다. 전북대학교 식품공학과 대학원생 10 명을 패널로 선정하여 실험의 목적과 관능적 품질요소를 잘 인식하도록 설명하고 예비실험을 통하여 훈련시킨 후 9점 평점법(scoring test)을 이용하여 실시하였다. 전 시료에 대한 관능적 특성이 다음 시료에 영향을 주지 않도록 하기 위해 각 시료의 검사 전에는 입안을 헹구도록 물을 제공하 였으며, 시료의 평가항목은 색(color), 향미(flavor), 맛 (taste), 쓴맛(bitterness), 조직감(hardness), 전반적 기호도 (overall-acceptability)의 6가지 특성에 대하여 매우 좋다는 9점, 매우 싫다는 1점으로 평가하였다.

\section{통계처리}

모든 실험은 SAS package(9.3, SAS Institute Inc., Cary, $\mathrm{NC}, \mathrm{USA}$ )를 이용하여 $\mathrm{p}<0.05$ 수준에서 Duncan's multiple range test에 의하여 시료간의 유의성을 검정하였고 데이터 는 3 반복의 평균값으로 나타내었다.

\section{결과 및 고찰}

\section{쌈무의 $\mathrm{pH}$, 적정산도의 변화}

염화칼슘 처리에 따른 온도별 저장기간 동안의 쌈무들의 $\mathrm{pH}$, 적정산도의 변화는 Table 2 와 같다. 각 농도별로 염화칼 슘 첨가 후 저장 전 쌈무들의 $\mathrm{pH}$ 범위는 약 3.8 4.0이었으며, 저장온도 $4^{\circ} \mathrm{C}$ 와 $50^{\circ} \mathrm{C}$ 의 시료들은 $28^{\circ}$ 일 동안의 저장기간에 도 저장 전 초기 $\mathrm{pH}$ 의 범위를 유지하였다. 그러나 저장온도 $25^{\circ} \mathrm{C}$ 에서 저장된 쌈무들의 $\mathrm{pH}$ 는 저장기간이 지날수록 $\mathrm{pH}$ 값이 낮아져 저장 28 일째는 모든 쌈무 시료들의 $\mathrm{pH}$ 범위가 약 3.3 3.5로 저장 전의 초기 $\mathrm{pH}$ 의 범위보다 0.5 가 낮아져 유의적으로 차이가 있었다 $(\mathrm{p}<0.05)$. 쌈무들의 적정산도에 있어서, 저장 전 쌈무 시료들의 적정산도는 약 2.7 3.0(\%, $\mathrm{w} / \mathrm{v})$ 이였다. 28 일 저장기간 동안 $4^{\circ} \mathrm{C}$ 와 $50^{\circ} \mathrm{C}$ 에서 저장된 시료들의 적정산도는 약간의 변화가 있었으나 저장 전 초기 의 쌈무 총산도의 범위에 크게 벗어나지는 않았다. 그러나 $25^{\circ} \mathrm{C}$ 에서 저장된 쌈무 시료들의 총산도 범위는 4.6 5.2(\%, $\mathrm{w} / \mathrm{v})$ 으로 저장 전 초기의 쌈무 총산도의 범위보다 $1.9 \sim 2.2(\%, \mathrm{w} / \mathrm{v})$ 가 증가되어 유의적으로 차이가 있었다 $(\mathrm{p}<0.05) . \mathrm{pH}$ 와 적정산도의 변화는 염화칼슘과 블렌칭을 처리한 오이지의 결과(7)에서처럼 미생물 성장과 밀접한 관계가 있는 것으로 생각되며, 이에 따라 $4^{\circ} \mathrm{C}$ 와 $50^{\circ} \mathrm{C}$ 에서 저장된 쌈무 시료들과는 달리 미생물 생육이 적당한 온도인

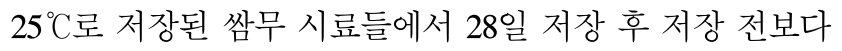
$\mathrm{pH}$ 는 낮아지고 적정산도가 증가된 것으로 판단된다.

\section{색도의 변화}

염화칼슘이 첨가된 쌈무들의 색도 변화는 Table 3에 나타 내었다. $4^{\circ} \mathrm{C}$ 에서 저장된 쌈무 시료들은 저장 14 일 후 근소한
차이 내지 감지할 수 있는 정도의 차이를 나타내었으며,

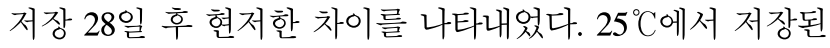
쌈무의 경우 저장 28 일 후 모든 처리구에서 극히 현저한 차이를 나타내었으며, $50^{\circ} \mathrm{C}$ 에서 저장된 시료들은 저장 14 일 후부터 다른 계통의 색으로 나타났다. 저장기간 동안 쌈무들의 명도는 온도가 높을수록 저장기간이 길어질수록 감소한 것으로 이는 Jung 등(13)에 의해 보고된 단무지의 명도 변화와 유사한 경향을 보였다. 이에 따라 저장기간 동안 쌈무의 색도 유지는 염화칼슘 첨가와는 관련이 없어 보이며 온도에 의해서 결정된다고 판단된다.

\section{쌈무의 경도와 씹힘성의 변화}

염화칼슘 첨가에 따른 저장기간 동안 쌈무 시료들의 경 도와 씹힘성의 변화를 측정한 결과는 Fig. 1 과 같다. $4^{\circ} \mathrm{C}$ 에 서 저장된 쌈무의 경도는 28 일 저장기간 동안 염화칼슘 $0.1 \sim 0.4 \%$ 처리에 따라 유의적으로 증가하였으며 $(\mathrm{p}<0.05)$, 무첨가 쌈무 시료와 $0.5 \%$ 처리 시료는 유의적으로 차이를 나타내지 않았다(Fig. 1A). $25^{\circ}$ C에서 저장된 쌈무 시료들의 경도는 $4^{\circ} \mathrm{C}$ 에서 저장된 쌈무 시료들 보다 경도가 다소 감소 되었으나, 염화칼슘 첨가 쌈무 시료들 대부분은 저장 전 초기 경도를 유지하였다. 그러나 염화칼슘 무첨가 쌈무 시 료의 경우 경도가 약 $15,300 \mathrm{~g}$ 에서 $11,800 \mathrm{~g}$ 으로 뚜렷이 감소됨을 확인하였다(p<0.05)(Fig. 1B). $50^{\circ} \mathrm{C}$ 에서 28 일 동안 저장한 결과에 있어서, 쌈무 시료들의 경도는 저장기간에 따라 현저한 차이를 보였으며, 염화칼슘 처리량이 증가 할 수록 저장기간 동안 쌈무 시료들의 경도가 농도에 따라 유의성을 보이며 높게 유지되고 있음을 확인 할 수 있었다 (Fig. 1C). 저장 0 일차 대조구의 경우 $15,314.4 \mathrm{~g}$ 을 나타내었 으며, 저장 28 일차 대조구의 경우 $1,757.1 \mathrm{~g}$ 로 유의적으로 크게 감소함을 보였다. 반면 염화칼슘 $0.5 \%$ 처리의 경우 저장 28 일차에 $10,265.5 \mathrm{~g}$ 를 나타내었다. 이와 같은 결과는 염화칼슘이 첨가된 오이지, 오이장아찌와 오이피클에서 보 고된 것과 같이 polygalacturonase와 같은 효소들의 활성 자체를 억제하거나 $(4,7,14)$ 또는 pectin esterase의 작용으로 생성되는 pectic acid에 칼슘이온과 결합하여 Ca-pectate를 형성 $(4,5)$ 함으로써 쌈무의 경도를 증가시킨 것으로 판단된 다. 쌈무 시료들의 씹힘성에 있어서는 전반적으로 경도의 결과와 유사하게 경향성이 나타나 씹힘성과 경도 간에 밀접 한 관계가 있음을 확인 할 수 있었다(Fig. 1D F).

\section{쌈무의 관능평가}

쌈무는 $4^{\circ} \mathrm{C}$ 냉장 유통을 한다는 점을 고려하여 관능평가 에 사용된 쌈무의 시료들은 $4^{\circ} \mathrm{C}$ 에서 28 일 동안 저장된 것을 사용하였고, 관능평가 결과는 Table 4 와 같다. 색, 향미와 쓴맛에 있어서는 염화칼슘 무처리 쌈무 시료들과 처리 쌈무 시료들 간에는 유의적 차이를 볼 수 없었으나, 맛, 경도와 전반적인 기호도에서 유의적 차이가 나타났다 $(\mathrm{p}<0.05)$. 특 
Table 2. Physicochemical properties of pickled radish wrap supplemented with various concentrations of $\mathrm{CaCl}_{2}$ for different durations of preservation

\begin{tabular}{|c|c|c|c|c|c|c|c|}
\hline \multirow{2}{*}{ Temp. } & \multirow{2}{*}{$\begin{array}{c}\mathrm{CaCl}_{2} \\
(\%)\end{array}$} & \multicolumn{3}{|c|}{$\mathrm{pH}$} & \multicolumn{3}{|c|}{ Titratable acidity $(\%, \mathrm{w} / \mathrm{v})$} \\
\hline & & 0 Day & 14 Day & 28 Day & 0 Day & 14 Day & 28 Day \\
\hline \multirow{6}{*}{4} & 0.0 & $3.99 \pm 0.06^{1) \mathrm{Aa}}$ & $3.92 \pm 0.02^{\mathrm{Ab}}$ & $3.91 \pm 0.02^{\mathrm{Db}}$ & $2.84 \pm 0.14 \mathrm{~B}^{\mathrm{Ca}}$ & $2.72 \pm 0.09^{\mathrm{Ca}}$ & $2.81 \pm 0.11^{\mathrm{Ba}}$ \\
\hline & 0.1 & $3.97 \pm 0.05^{\mathrm{Aa}}$ & $3.91 \pm 0.08^{\mathrm{ABa}}$ & $3.98 \pm 0.06^{\mathrm{BCa}}$ & $2.76 \pm 0.12^{\mathrm{Cb}}$ & $3.09 \pm 0.03^{\mathrm{Aa}}$ & $3.04 \pm 0.03^{\mathrm{Aa}}$ \\
\hline & 0.2 & $3.92 \pm 0.01^{\mathrm{ABb}}$ & $3.91 \pm 0.02^{\mathrm{ABb}}$ & $4.04 \pm 0.04^{\mathrm{ABa}}$ & $3.00 \pm 0.07^{\mathrm{ABa}}$ & $2.82 \pm 0.05^{\mathrm{Bb}}$ & $2.63 \pm 0.05^{\mathrm{Cc}}$ \\
\hline & 0.3 & $3.90 \pm 0.02^{\mathrm{ABCb}}$ & $3.83 \pm 0.02^{\mathrm{Cc}}$ & $3.95 \pm 0.01^{\mathrm{CDa}}$ & $3.02 \pm 0.07^{\mathrm{Aa}}$ & $3.03 \pm 0.05^{\mathrm{Aa}}$ & $2.69 \pm 0.02^{\mathrm{cb}}$ \\
\hline & 0.4 & $3.80 \pm 0.04^{\mathrm{Cc}}$ & $3.86 \pm 0.02^{\mathrm{ABbC}}$ & $4.07 \pm 0.03^{\mathrm{Aa}}$ & $3.02 \pm 0.04^{\mathrm{Aa}}$ & $2.90 \pm 0.05^{\mathrm{Bb}}$ & $3.01 \pm 0.05^{\mathrm{Aa}}$ \\
\hline & 0.5 & $3.86 \pm 0.11^{\mathrm{BCb}}$ & $3.85 \pm 0.01^{\mathrm{BCb}}$ & $4.03 \pm 0.01^{\mathrm{ABa}}$ & $3.06 \pm 0.07^{\mathrm{Aa}}$ & $2.83 \pm 0.03^{\mathrm{Bb}}$ & $2.99 \pm 0.07^{\mathrm{Aa}}$ \\
\hline \multirow{6}{*}{25} & 0.0 & $3.99 \pm 0.06^{\mathrm{Aa}}$ & $3.55 \pm 0.02^{\mathrm{Cb}}$ & $3.51 \pm 0.07^{\mathrm{Ab}}$ & $2.84 \pm 0.14^{\mathrm{BCc}}$ & $3.69 \pm 0.18^{\mathrm{Bb}}$ & $4.88 \pm 0.05^{\mathrm{Ba}}$ \\
\hline & 0.1 & $3.97 \pm 0.05^{\mathrm{Aa}}$ & $3.79 \pm 0.01^{\mathrm{Bb}}$ & $3.47 \pm 0.01^{\mathrm{Ac}}$ & $2.76 \pm 0.12^{\mathrm{Cc}}$ & $3.04 \pm 0.05^{\mathrm{Cb}}$ & $4.61 \pm 0.11^{\mathrm{Ca}}$ \\
\hline & 0.2 & $3.92 \pm 0.01^{\mathrm{ABa}}$ & $3.31 \pm 0.01^{\mathrm{Dc}}$ & $3.44 \pm 0.01^{\mathrm{Ab}}$ & $3.00 \pm 0.07^{\mathrm{ABc}}$ & $4.93 \pm 0.06^{\mathrm{Ab}}$ & $5.26 \pm 0.10^{\mathrm{Aa}}$ \\
\hline & 0.3 & $3.90 \pm 0.02^{\mathrm{ABCa}}$ & $3.87 \pm 0.08^{\mathrm{Aa}}$ & $3.49 \pm 0.01^{\mathrm{Ab}}$ & $3.02 \pm 0.07^{\mathrm{Ab}}$ & $3.06 \pm 0.05^{\mathrm{Cb}}$ & $4.44 \pm 0.06^{\mathrm{Da}}$ \\
\hline & 0.4 & $3.80 \pm 0.04^{\mathrm{Ca}}$ & $3.83 \pm 0.02^{\mathrm{ABa}}$ & $3.36 \pm 0.03^{\mathrm{Bb}}$ & $3.02 \pm 0.04^{\mathrm{Ab}}$ & $3.13 \pm 0.11^{\mathrm{Cb}}$ & $5.25 \pm 0.05^{\mathrm{Aa}}$ \\
\hline & 0.5 & $3.86 \pm 0.11^{\mathrm{BCa}}$ & $3.60 \pm 0.03^{\mathrm{Cb}}$ & $3.51 \pm 0.06^{\mathrm{Ab}}$ & $3.06 \pm 0.07^{\mathrm{Ac}}$ & $3.64 \pm 0.05^{\mathrm{Bb}}$ & $4.67 \pm 0.15^{\mathrm{Ca}}$ \\
\hline \multirow{6}{*}{50} & 0.0 & $3.99 \pm 0.06^{\mathrm{Aa}}$ & $3.89 \pm 0.04^{\mathrm{Ab}}$ & $3.88 \pm 0.01^{\mathrm{Bb}}$ & $2.84 \pm 0.14^{\mathrm{BCa}}$ & $3.01 \pm 0.20^{\mathrm{Ca}}$ & $3.03 \pm 0.11^{\mathrm{Ba}}$ \\
\hline & 0.1 & $3.97 \pm 0.05^{\mathrm{Aa}}$ & $3.88 \pm 0.01^{\mathrm{Ab}}$ & $3.89 \pm 0.02^{\mathrm{Bb}}$ & $2.76 \pm 0.12^{\mathrm{Cc}}$ & $3.17 \pm 0.07^{\mathrm{BCa}}$ & $2.94 \pm 0.05^{\mathrm{BCb}}$ \\
\hline & 0.2 & $3.92 \pm 0.01^{\mathrm{ABa}}$ & $3.80 \pm 0.01^{\mathrm{Bb}}$ & $3.92 \pm 0.04^{\mathrm{ABa}}$ & $3.00 \pm 0.07^{\mathrm{ABb}}$ & $3.39 \pm 0.03^{\mathrm{Aa}}$ & $2.90 \pm 0.09^{\mathrm{BCb}}$ \\
\hline & 0.3 & $3.90 \pm 0.02^{\mathrm{ABCa}}$ & $3.75 \pm 0.01^{\mathrm{Cb}}$ & $3.86 \pm 0.07^{\mathrm{Ba}}$ & $3.02 \pm 0.07^{\mathrm{Ac}}$ & $3.53 \pm 0.05^{\mathrm{Aa}}$ & $3.22 \pm 0.08^{\mathrm{Ab}}$ \\
\hline & 0.4 & $3.80 \pm 0.04^{\mathrm{cb}}$ & $3.80 \pm 0.01^{\mathrm{Bb}}$ & $3.93 \pm 0.01^{\mathrm{ABa}}$ & $3.02 \pm 0.04^{\mathrm{Ab}}$ & $3.18 \pm 0.05^{\mathrm{BCa}}$ & $2.81 \pm 0.03^{\mathrm{Cc}}$ \\
\hline & 0.5 & $3.86 \pm 0.11^{\mathrm{BCab}}$ & $3.81 \pm 0.02^{\mathrm{Bb}}$ & $3.97 \pm 0.04^{\mathrm{Aa}}$ & $3.06 \pm 0.07^{\mathrm{Ab}}$ & $3.20 \pm 0.05^{\mathrm{Ba}}$ & $2.87 \pm 0.03^{\mathrm{Cc}}$ \\
\hline
\end{tabular}

${ }^{1)}$ Values represent mean $\pm \mathrm{SD}$ of three independent experiments.

${ }^{\mathrm{A}-\mathrm{D}}$ Means with the same alphabet in each temperature column are not significantly different at $\mathrm{p}<0.05$.

${ }^{\mathrm{a} c \mathrm{c}}$ Means with the same alphabet in each row are not significantly different by storage time at $\mathrm{p}<0.05$

Table 3. Color of pickled radish wrap supplemented with various concentrations of $\mathrm{CaCl}_{2}$ for different durations of preservation

\begin{tabular}{|c|c|c|c|c|c|c|c|c|c|c|c|c|}
\hline \multirow{2}{*}{ Temp. } & \multirow{2}{*}{$\begin{array}{c}\mathrm{CaCl}_{2} \\
(\%)\end{array}$} & \multicolumn{3}{|c|}{0 Day } & \multicolumn{4}{|c|}{14 Day } & \multicolumn{4}{|c|}{28 Day } \\
\hline & & $\mathrm{L}$ & $\mathrm{a}$ & $\mathrm{b}$ & $\mathrm{L}$ & $\mathrm{a}$ & $\mathrm{b}$ & $\Delta \mathrm{E}$ & $\mathrm{L}$ & $\mathrm{a}$ & $\mathrm{b}$ & $\Delta \mathrm{E}$ \\
\hline \multirow{6}{*}{4} & 0.0 & $48.85 \pm 0.48$ & $-1.84 \pm 0.28$ & $-1.07 \pm 0.17$ & $50.02 \pm 0.13$ & $-3.02 \pm 0.44$ & $-1.66 \pm 0.84$ & 1.76 & $45.49 \pm 0.02$ & $-3.42 \pm 0.10$ & $-1.68 \pm 0.03$ & 3.76 \\
\hline & 0.1 & $47.78 \pm 0.17$ & $-2.18 \pm 0.09$ & $-0.14 \pm 0.25$ & $50.20 \pm 0.02$ & $-3.22 \pm 0.07$ & $-0.52 \pm 0.03$ & 2.63 & $46.37 \pm 0.02$ & $-3.34 \pm 0.08$ & $-0.30 \pm 0.38$ & 1.84 \\
\hline & 0.2 & $51.23 \pm 0.01$ & $-2.25 \pm 0.02$ & $-0.22 \pm 0.01$ & $51.10 \pm 0.02$ & $-3.26 \pm 0.05$ & $0.37 \pm 0.02$ & 1.02 & $44.65 \pm 0.04$ & $-3.07 \pm 0.15$ & $1.02 \pm 0.01$ & 6.66 \\
\hline & 0.3 & $52.38 \pm 0.01$ & $-1.90 \pm 0.03$ & $-0.80 \pm 0.09$ & $50.78 \pm 0.06$ & $-3.09 \pm 0.10$ & $-0.08 \pm 0.13$ & 1.99 & $44.56 \pm 0.00$ & $-2.96 \pm 0.00$ & $-2.36 \pm 0.01$ & 8.21 \\
\hline & 0.4 & $51.13 \pm 0.18$ & $-2.19 \pm 0.18$ & $1.85 \pm 0.23$ & $50.50 \pm 0.03$ & $-3.14 \pm 0.22$ & $-1.18 \pm 0.11$ & 1.14 & $44.11 \pm 0.01$ & $-3.46 \pm 0.06$ & $0.23 \pm 0.01$ & 7.27 \\
\hline & 0.5 & $46.69 \pm 0.14$ & $-2.03 \pm 0.10$ & $0.02 \pm 0.26$ & $50.21 \pm 0.02$ & $-3.25 \pm 0.06$ & $-0.13 \pm 0.05$ & 3.73 & $45.67 \pm 0.01$ & $-3.24 \pm 0.08$ & $0.38 \pm 0.00$ & 1.66 \\
\hline \multirow{6}{*}{25} & 0.0 & $48.85 \pm 0.48$ & $-1.84 \pm 0.28$ & $-1.07 \pm 0.17$ & $42.96 \pm 0.01$ & $-1.69 \pm 0.04$ & $3.67 \pm 0.04$ & 7.56 & $42.62 \pm 0.01$ & $-0.26 \pm 0.04$ & $5.62 \pm 0.02$ & 9.28 \\
\hline & 0.1 & $47.78 \pm 0.17$ & $-2.18 \pm 0.09$ & $-0.14 \pm 0.25$ & $41.54 \pm 0.02$ & $-0.94 \pm 0.05$ & $2.81 \pm 0.03$ & 7.18 & $35.52 \pm 0.01$ & $-0.79 \pm 0.06$ & $3.76 \pm 0.01$ & 13.06 \\
\hline & 0.2 & $51.23 \pm 0.01$ & $-2.25 \pm 0.02$ & $-0.22 \pm 0.01$ & $46.93 \pm 0.17$ & $-2.83 \pm 0.34$ & $2.03 \pm 0.17$ & 4.65 & $36.56 \pm 0.01$ & $-0.59 \pm 0.05$ & $3.47 \pm 0.06$ & 15.09 \\
\hline & 0.3 & $52.38 \pm 0.01$ & $-1.90 \pm 0.03$ & $-0.80 \pm 0.09$ & $44.12 \pm 0.16$ & $-3.13 \pm 0.12$ & $2.35 \pm 0.16$ & 8.70 & $40.74 \pm 0.01$ & $-1.45 \pm 0.02$ & $3.27 \pm 0.01$ & 12.12 \\
\hline & 0.4 & $51.13 \pm 0.18$ & $-2.19 \pm 0.18$ & $1.85 \pm 0.23$ & $45.49 \pm 0.13$ & $-3.29 \pm 0.34$ & $5.78 \pm 0.22$ & 9.03 & $42.84 \pm 0.02$ & $-2.23 \pm 0.05$ & $1.24 \pm 0.02$ & 8.64 \\
\hline & 0.5 & $46.69 \pm 0.14$ & $-2.03 \pm 0.10$ & $0.02 \pm 0.26$ & $47.38 \pm 0.14$ & $-2.42 \pm 0.18$ & $4.55 \pm 0.07$ & 4.75 & $39.93 \pm 0.02$ & $-1.15 \pm 0.12$ & $2.89 \pm 0.01$ & 7.46 \\
\hline \multirow{6}{*}{50} & 0.0 & $48.85 \pm 0.48$ & $-1.84 \pm 0.28$ & $-1.07 \pm 0.17$ & $27.32 \pm 0.01$ & $2.74 \pm 0.04$ & $7.47 \pm 0.06$ & 23.61 & $27.30 \pm 0.01$ & $2.54 \pm 0.03$ & $7.32 \pm 0.01$ & 23.54 \\
\hline & 0.1 & $47.78 \pm 0.17$ & $-2.18 \pm 0.09$ & $-0.14 \pm 0.25$ & $31.76 \pm 0.00$ & $2.70 \pm 0.03$ & $8.49 \pm 0.11$ & 19.02 & $25.90 \pm 0.00$ & $3.24 \pm 0.00$ & $6.72 \pm 0.01$ & 23.68 \\
\hline & 0.2 & $51.23 \pm 0.01$ & $-2.25 \pm 0.02$ & $-0.22 \pm 0.01$ & $29.73 \pm 0.00$ & $3.40 \pm 0.07$ & $8.18 \pm 0.03$ & 23.56 & $29.49 \pm 0.00$ & $2.64 \pm 0.03$ & $8.24 \pm 0.00$ & 23.63 \\
\hline & 0.3 & $52.38 \pm 0.01$ & $-1.90 \pm 0.03$ & $-0.80 \pm 0.09$ & $28.21 \pm 0.00$ & $2.63 \pm 0.00$ & $6.92 \pm 0.10$ & 25.57 & $29.07 \pm 0.02$ & $2.85 \pm 0.13$ & $8.38 \pm 0.02$ & 25.25 \\
\hline & 0.4 & $51.13 \pm 0.18$ & $-2.19 \pm 0.18$ & $1.85 \pm 0.23$ & $31.36 \pm 0.00$ & $2.56 \pm 0.06$ & $8.69 \pm 0.01$ & 22.60 & $25.86 \pm 0.00$ & $3.45 \pm 0.07$ & $7.26 \pm 0.03$ & 27.23 \\
\hline & 0.5 & $46.69 \pm 0.14$ & $-2.03 \pm 0.10$ & $0.02 \pm 0.26$ & $29.39 \pm 0.10$ & $3.05 \pm 0.40$ & $7.69 \pm 0.08$ & 19.65 & $23.84 \pm 0.01$ & $3.62 \pm 0.12$ & $6.79 \pm 0.02$ & 24.53 \\
\hline
\end{tabular}


Table 4. Sensory evaluation of pickled radish wrap supplemented with various concentrations of $\mathrm{CaCl}_{2}$ and preserved for 28 days at $4{ }^{\circ} \mathrm{C}$

\begin{tabular}{ccccccc}
\hline \multirow{2}{*}{$\mathrm{CaCl}_{2}(\%)$} & \multicolumn{5}{c}{ Sensory test } \\
\cline { 2 - 7 } & Color & Flavor & Taste & Bitterness & Hardness & Overall acceptability \\
\hline 0.0 & $8.43 \pm 0.79^{\mathrm{a}}$ & $7.57 \pm 0.98^{\mathrm{a}}$ & $5.43 \pm 2.30^{\mathrm{b}, \mathrm{d}}$ & $5.29 \pm 2.36^{\mathrm{a}}$ & $6.14 \pm 1.86^{\mathrm{a}, \mathrm{b}}$ & $6.00 \pm 1.91^{\mathrm{a}, \mathrm{b}, \mathrm{c}}$ \\
0.1 & $8.43 \pm 0.79^{\mathrm{a}}$ & $7.57 \pm 0.98^{\mathrm{a}}$ & $6.29 \pm 1.25^{\mathrm{a}, \mathrm{b}}$ & $6.00 \pm 2.00^{\mathrm{a}}$ & $7.29 \pm 0.76^{\mathrm{a}, \mathrm{b}}$ & $6.43 \pm 1.51^{\mathrm{a}, \mathrm{b}}$ \\
0.2 & $8.14 \pm 0.69^{\mathrm{a}}$ & $7.29 \pm 1.11^{\mathrm{a}}$ & $3.57 \pm 1.81^{\mathrm{c}}$ & $4.43 \pm 2.30^{\mathrm{a}}$ & $6.00 \pm 1.00^{\mathrm{a}, \mathrm{b}}$ & $4.14 \pm 1.46^{\mathrm{c}}$ \\
0.3 & $8.14 \pm 0.69^{\mathrm{a}}$ & $6.86 \pm 2.19^{\mathrm{a}}$ & $6.00 \pm 2.00^{\mathrm{a}, \mathrm{b}}$ & $5.57 \pm 1.62^{\mathrm{a}}$ & $6.00 \pm 1.00^{\mathrm{a}, \mathrm{b}}$ & $6.86 \pm 1.46^{\mathrm{a}, \mathrm{b}}$ \\
0.4 & $8.14 \pm 0.69^{\mathrm{a}}$ & $7.29 \pm 1.11^{\mathrm{a}}$ & $7.86 \pm 1.35^{\mathrm{a}}$ & $5.57 \pm 1.99^{\mathrm{a}}$ & $7.71 \pm 1.25^{\mathrm{a}}$ & $7.71 \pm 1.38^{\mathrm{a}}$ \\
0.5 & $8.14 \pm 0.69^{\mathrm{a}}$ & $6.57 \pm 2.37^{\mathrm{a}}$ & $4.57 \pm 2.23^{\mathrm{b}, \mathrm{c}}$ & $4.86 \pm 2.48^{\mathrm{a}}$ & $5.71 \pm 2.43^{\mathrm{b}}$ & $5.14 \pm 2.48^{\mathrm{b}, \mathrm{c}}$ \\
\hline
\end{tabular}

${ }^{a-d}$ All values represent mean $\pm \mathrm{SD}$, different superscripts in the same column indicate significant differences at $\mathrm{p}<0.05$.
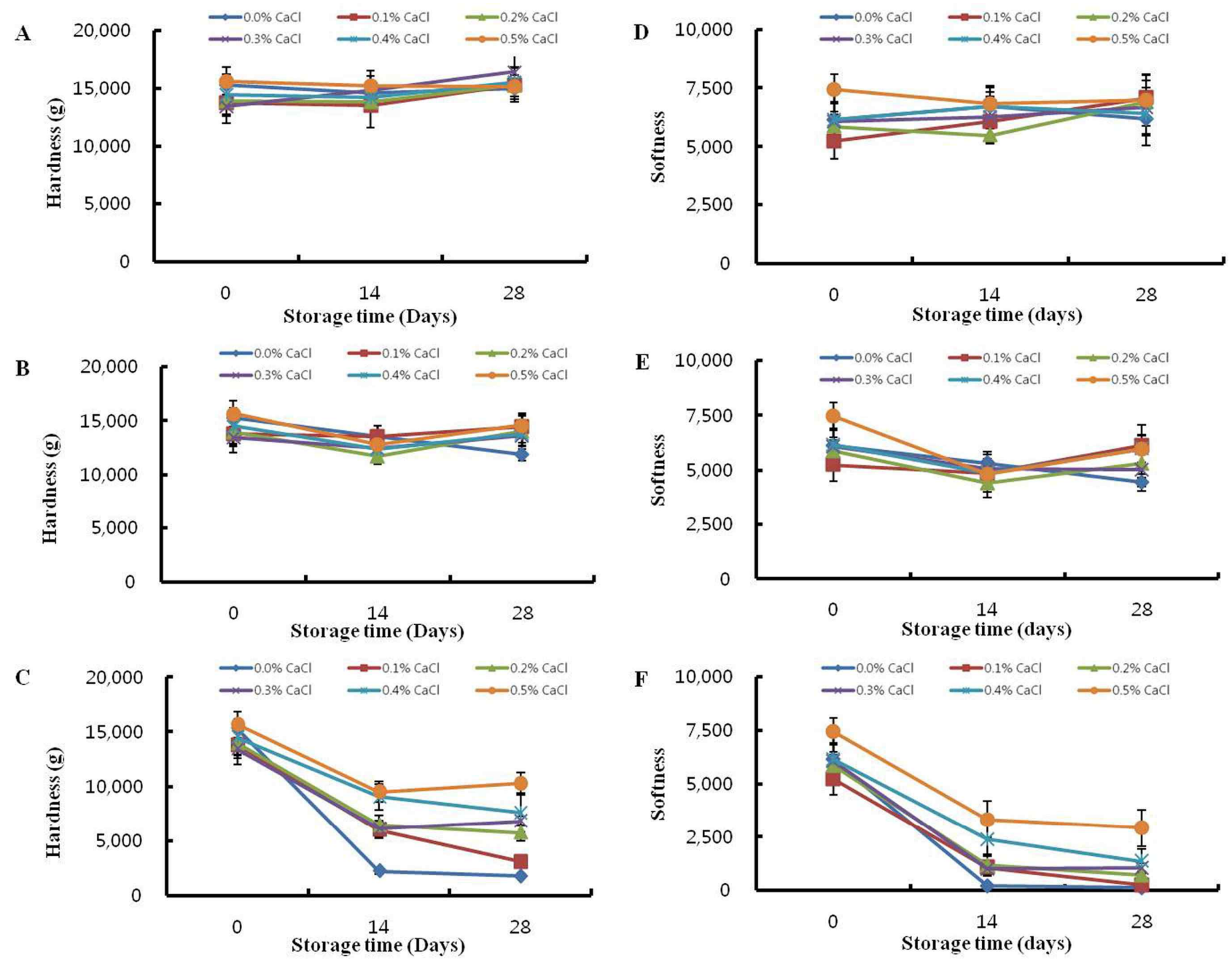

Fig. 1. Changes in hardness and softness of pickled radish wrap supplemented with various concentration of $\mathrm{CaCl} 2$ for different durations of preservation at $4^{\circ} \mathrm{C}, 25^{\circ} \mathrm{C}$, or $50^{\circ} \mathrm{C}$.

$\mathrm{A} \sim \mathrm{C}$, hardness of pickled radish wrap preserved at $4{ }^{\circ} \mathrm{C}(\mathrm{A}), 25^{\circ} \mathrm{C}(\mathrm{B})$, or $50^{\circ} \mathrm{C}(\mathrm{C})$; D F, hardness of pickled radish wrap preserved at $4^{\circ} \mathrm{C}(\mathrm{D}), 25^{\circ} \mathrm{C}(\mathrm{E})$, or $50^{\circ} \mathrm{C}(\mathrm{F})$. Data represent the means from ten samples. Error bars, SD.

히 쓴맛은 염화칼슘의 가장 큰 단점으로 첨가량이 증가됨에 따라 쓴맛 느낄 것으로 생각 되었지만 관능적으로는 염화칼 슘 무첨가 쌈무와 유의적 차이가 없어 염화칼슘을 쌈무에
$0.5 \%$ 까지는 첨가해도 쌈무의 품질에 큰 영향을 주지 않을 것으로 판단되지만 전반적인 관능평가 항목에서 낮은 점수 를 받아 $0.5 \%$ 염화칼슘이 첨가된 쌈무는 선호하지 않음을 
알 수 있었다. 전반적인 기호도에서 가장 높은 점수를 받은 것은 $0.4 \%$ 염화칼슘이 첨가된 쌈무로 맛과 경도에서 높은 점수를 받아 선호하는 것으로 판단된다. $0.3 \%$ 염화칼슘이 첨가된 쌈무를 두 번째로 선호하는 것으로 볼 때, 관능품질 을 유지하면서 염화칼슘 첨가에 따른 쌈무의 저장기간을 연장할 수 있는 첨가제로써의 최대한 활용할 수 있는 첨가 농도는 0.3 0.4\% 사이가 적절한 것으로 판단된다.

\section{요 약}

염화칼슘 농도를 달리한 쌈무의 조직감 개선 효과, 물리. 화학적 특성 및 관능평가를 비교하였다. 염화칼슘 첨가 후 저장 전 쌈무들의 $\mathrm{pH}$ 와 총산도 범위는 각각 약 3.8 4.0와 $2.7 \sim 3.0(\%, \mathrm{w} / \mathrm{v})$ 이었으며, 28 일 동안의 저장기간 동안 저장 온도 $4^{\circ} \mathrm{C}$ 와 $50^{\circ} \mathrm{C}$ 의 시료들은 저장 전 초기 $\mathrm{pH}$ 와 총산도의 범위를 유지하였다. 그러나 저장온도 $25^{\circ} \mathrm{C}$ 에서 쌈무 시료 들은 저장 전 초기 $\mathrm{pH}$ 범위보다 0.5 가 낮아졌고 총산도는 $1.9 \sim 2.2(\%, \mathrm{w} / \mathrm{v})$ 가 증가되어졌다. 염화칼슘의 첨가에 따른 쌈무 시료들의 색도를 측정한 결과, 28 일 저장동안 $4^{\circ} \mathrm{C}$ 에서 저장된 쌈무 시료들은 현저한 차이를 나타내었으나 $(\triangle \mathrm{E}$ 값 $1.66 \sim 8.21) 50^{\circ} \mathrm{C}$ 에서 저장된 시료들은 다른 계통의 색으로 ( $\triangle \mathrm{E}$ 값 23 27) 큰 변화를 보였다. 쌈무 시료들의 경도에 있어서, 저장온도 $4^{\circ} \mathrm{C}$ 와 $25^{\circ} \mathrm{C}$ 에서 $28^{\circ}$ 일 동안 저장된 쌈무 시료들의 경도는 저장 전 쌈무 시료들의 경도와 큰 차이를 보이지 않았고, $50^{\circ} \mathrm{C}$ 에서는 염화칼슘 처리량이 증가 할수 록 경도가 높게 유지되고 있음을 확인 할 수 있었다. 쌈무 시료들의 씹힘성에 있어서는 전반적으로 경도의 결과와 유사한 경향을 보였다. 이로써 염화칼슘처리로 쌈무의 조 직감을 향상시킬 수 있음을 확인하였다. $4{ }^{\circ} \mathrm{C}$ 에서 28 일 동안 저장된 쌈무 시료들의 관능평가 결과, $0.4 \%$ 염화칼슘이 첨가된 쌈무 시료가 맛, 경도와 전반적인 기호도에서 가장 높은 점수를 받아 유통 저장기간 동안 관능품질을 유지하면 서 쌈무의 조직감을 유지시킬 수 있는 염화칼슘 첨가량이라 판단된다.

\section{감사의 글}

본 연구는 농림축산식품부 고부가 식품산업 전문인력 양성 사업에 의해 이루어진 것임.

\section{References}

1. Rho JO, Kim YO, Lee YS (2013) Quality characteristics of pickled color radish and sensory evaluation by elementary, middle, high and university students. J East Asian Soc Dietary Life, 23, 569-576

2. Korea Food and Drug Administration (2008) Korea Food Code. Moonyoungsa, Seoul, Korea, p 156

3. Rhee HS, Lee GJ (1994) Effects of preheating treatment and chitosan addition on the textural properties of Korean radish during salting. Korean J Dietary Culture, 9, 53-59

4. Lee HY, Jung ST, Park HJ (1995) The changes in firmness, $\mathrm{Ca}$ content and polygalacturonase and pectinesterase activities during Oyijangachi preparation. J Korean Soc Food Nutr, 24, 796-802

5. Suntarinen M, Autio K (2004) Improving the texture of frozen fruit : the case of berries. In : Texture in food Vol 2 Solid foods, Kilcast D (Editor), Woodhead Publishing Limited, Cambridge, England, p 392-393

6. Oh YA, Kim SD (1995) Effect of salting in salt solution added calcium chloride on the fermentation of Baechu kimchi. J East Asian Soc Dietary Life, 5, 287-298

7. Kim CH, Yang YH, Kim MR (2005) Effect of blanching and $\mathrm{CaCl}_{2}$ on the quality characteristics of Oiji prepared by dry salting method during storage. J East Asian Soc Dietary Life, 15, 219-225

8. Oh HI, Park JM, Jang JH (1997) Effect of desalting on the physicochemical and sensory characteristics of Danmuji. Korean J Food Nutr, 10, 439-445

9. Park HW, Lee SA, Kim YH, Kim YM, Cha HS, Park JD (2007) Effects of calcium chloride treatment and modified atmosphere packaging on the quality change of 'Fuji' Apple. Korean J Food Preserv, 14, 457-461

10. Choi YS, Lee KM, Seo GS, Kim MK, Hwang YS (2010) Effect of preharvest treatment of $\mathrm{CaCl}_{2}$ and alkalinereduced water on the quality oyster mushroom during storage, J Agri Sci, 37, 355-360

11. Korea Food and Drug Administration (2009) Korea Food Additives Code. Moonyoungsa, Seoul, Korea, p 266

12. Jung HA, Kim AN, Park SH, Kim MJ, Yoo YJ, Lee YR (2011) Study development of salad dressing with added sea tangle (Laminaria japonica). Korean J Food Nutr, 24, 520-527

13. Jung HA, Park CS, Park SH (2012) Monitoring of quality characteristics of Danmooji product storage temperature establishment. Korean J Food Preserv, 19, 818-824

14. Hudson JM, Buescher RW (1980) Prevention of soft center development in large whole cucumber pickle by calcium. J Food Sci, 45, 1450-1451 